Received 6 November 2018 Accepted 28 November 2018 Link to DOI: 10.25220/WNJ.V02.i2.0005

Journal Website: www.worldnutrijournal.org

\section{Prediction of Post-operative Survival of Colorectal Cancer Patient by Using the Prognostic Nutritional Index: An Evidence-based Case Report}

Nurul RM Manikam ${ }^{1}$, Yosua Y Kristian ${ }^{1}$, Luana Lidwina ${ }^{1}$, Ayu Diandra Sari ${ }^{1}$, Diana Sunardi ${ }^{1}$

1. Department of Nutrition, Faculty of Medicine, Universitas Indonesia, Cipto Mangunkusumo General Hospital, Jakarta, Indonesia

\begin{abstract}
Introduction Colorectal cancer patients may be treated with several modalities and one of them is surgical treatment. Surgery in cancer patients is a risky procedure and may not always result in prolonged survival. Therefore, before receiving any recommended treatment, the patient's prognosis has to be assessed and defined properly. Several methods are available to assess the prognosis of cancer patients; one of them is the prognostic nutritional index (PNI).

Objective This study aimed to predict the survival of a colorectal cancer patient postoperatively by calculating the preoperative PNI score.

Method Literature searching was done using inclusion and exclusion criteria on two databases, i.e. the PubMed and the Cochrane Library. The outcome was survival (disease-free survival, relapse-free survival, or overall survival).

Results Five articles that address the clinical question were retrieved. All indicated that a patient with low PNI score $(<44.5)$ had a shorter overall survival (HR between 1.92 and 3.98 with all $p$ values were $<0.05)$.

Conclusion Pre-operative PNI score can be used to assess the overall survival of a colorectal cancer patient who underwent surgical resection. Patients with a PNI score $\geq 44.5$ had better survival than lower PNI score.
\end{abstract}

Keywords prognostic nutritional index, post-operative colorectal cancer, survival

\section{Clinical Scenario}

Mr. MR, aged 67 years old, was complaining to have bloating and incomplete bowel emptying in the last 8 months. He might have 1-2 defecations per day but the consistency was soft or liquid for about $1 / 2$ glass each stool; the color is pale yellow and might be accompanied by dark red blood. He denied having

\footnotetext{
Corresponding author:

Nurul Ratna Mutu Manikam, MD, MSc

Department of Nutrition, Faculty of Medicine,

Universitas Indonesia

Email:nurul.ratna@hotmail.com
}

nausea or vomitus and no black stool. During this time, his food intake was unchanged but he felt that his clothing was getting looser. His family also told him that he was getting thinner. Mr. MR visited a doctor in Hospital $\mathrm{K}$ and underwent a complete laboratory check-up. The results at 2 weeks before coming to our clinic was as follows: $\mathrm{Hb} 9.6 \mathrm{~g} / \mathrm{dL}$, leukocyte count $8000 / \mathrm{mm}^{3}$, platelet count: $200.000 / \mathrm{uL}$, lymphocyte count $2000 / \mathrm{m}^{3}$, and albumin $2.8 \mathrm{~g} / \mathrm{dL}$. A tumor was found and a biopsy confirmed that it was ascending colon cancer T3N0M0. The doctor recommended complete surgical resection of the tumor, followed by chemotherapy if needed. The patient asked more time to think and to discuss with his family. His 
family suggested him to find another doctor for another opinion. Therefore, Mr. MR came to this clinic to find a second opinion for the recommended surgical treatment. He asked how long his chance to live if he takes the procedure.

\section{Introduction}

Colorectal cancer is the third most common malignancies worldwide with mortality rate rank the second after lung cancer. ${ }^{1}$ According to GLOBOCAN 2018 database, over 1.8 million new colorectal cancer cases are estimated to occur in 2018, with 1 mortality in 10 cases. The incidence of colorectal cancer in south-eastern Asia is $5-9 \%$ of all cancers, ${ }^{2}$ otherwise the incidence rate of colorectal cancer per 100.000 population in Indonesia is 19.1 (men) and 15.6 (female). ${ }^{3}$ Colorectal cancer in Indonesia has increased sharply due to the changing pattern of eating habit towards a high fat-low fiber diet or a diet high in processed meat consumption. Surgical management is offered to the patient whenever feasible and may be followed by chemotherapy. ${ }^{4}$ Colorectal cancer has a high recurrence rate after surgery; this is an important consideration for clinicians when choosing the best treatment for the patient. Assessment of prognostic factor is needed to assist clinicians in selecting the right treatment and education for the patient. ${ }^{5}$ One of the prognostic factors that can be used is the prognostic nutritional index (PNI). It is calculated pre-operatively as follows: PNI $=10 \mathrm{x}$ serum albumin $(\mathrm{g} / \mathrm{dL})+0.005 \mathrm{x}$ total lymphocyte count $\left(\right.$ per $\left.\mathrm{mm}^{3}\right)$. Assessment of PNI was first done by Onodera et al to predict patients who underwent gastrointestinal surgery (colorectal, gastric, hepatocelullar, pancreatic cancer). ${ }^{6}$ The PNI is a method to objectively assess the patient's prognosis, which is relatively cheap and easy to use by the clinicians.

\section{Clinical Question \\ P: Post-operative adult patient with colorectal cancer \\ I: The Prognostic Nutritional Index (PNI) score C: - \\ O: Post-operative survival}

Clinical question: How does the prognostic nutritional index predict the postoperative survival of colorectal cancer patients?

\section{Methods}

\section{Strategy of Article Searching}

Literature searching was done on PubMed and Cochrane Library on October 9, 2018 (Table 1).

\section{Strategy of Article Selection \\ Eligibility Criteria}

Article selection was based on the inclusion and exclusion criteria, which addressed the clinical question. The inclusion criteria were: 1) the study subjects were adult patients (aged $\geq 18$ years); 2 ) subjects were diagnosed as colorectal cancer of various stages and underwent surgical treatment; 3 ) the PNI calculation was done pre-operatively; 4) the study population was originated from Asia and 5) the cutoff PNI score was set between 44 and 46. The exclusion criteria were 1) non-English journal and 2) no available full text.

\section{Method of Critical Appraisal}

Critical appraisal was done by all authors and by using the method of critical appraisal according to the Center of Evidence Based Medicine (www.cebm.net) for prognostic studies that has been modified in Indonesian language.

\section{Results}

Based on the results from the two databases and by assessing the inclusion and exclusion criteria, we obtained 5 eligible articles to be included as references for a critical appraisal (Figure 1).

Selected articles were studies with cohort design, either prospective or retrospective. The number of study subjects should be more than 200 patients in the adult group. Patients should be followed-up at least for 60 months. Study characteristics is shown in Table 2. All studies had a level of evidence of 2 that were individual cohort studies. All their results showed that low PNI score indicated a shorter overall survival. The validity criteria are given in Table 3. There was a report that did not meet the criteria of applicability and importance, i.e. the study by Park et al. 


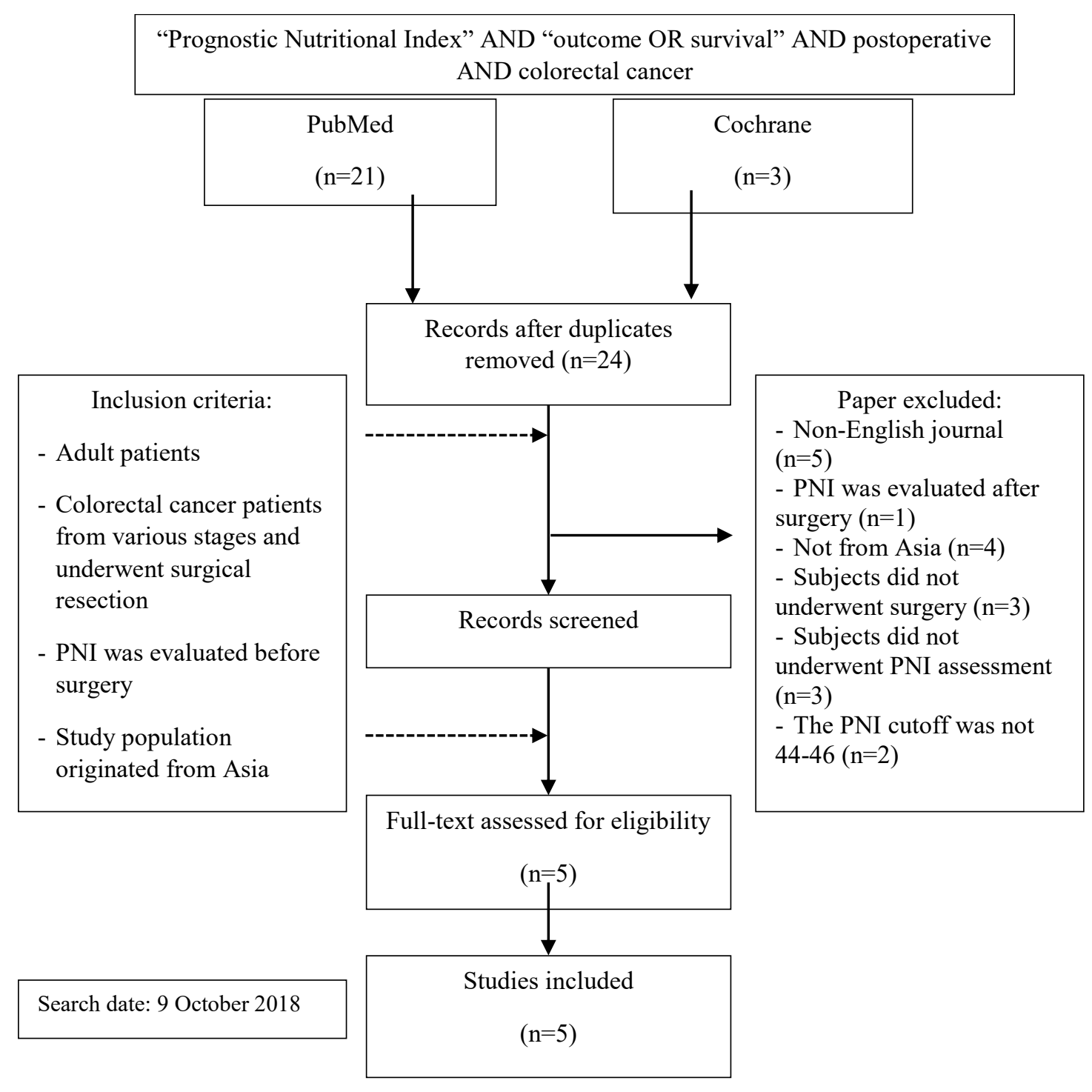

Figure 1. PRISMA Flowchart

\section{Discussion}

Mohri et al did a retrospective study by assessing patients who underwent colorectal cancer resection between January 2001 and December 2016 in the Department of Gastrointestinal Surgery at Mie University Hospital, Japan. The study involved 365 subjects with colorectal cancer from stage I to IV. Blood test was done before surgery and was used to count PNI; the score was low if PNI $<45$. The study results showed that PNI score can be a good predictor of postoperative complication $(\mathrm{OR}=1.58$ [95\% CI 1.03 to 2.42$] ; p=0.04)$ and overall survival $(\mathrm{OR}=2.25[95 \%$ CI 1.42 to 3.59$] ; p<0.0001)$ of patients with colorectal cancer. ${ }^{5}$
Cao et al did a retrospective study in an institution in China under the National Health and Family Planning Commission. The study was held between January 2009 and January 2012 involving 228 study subjects who underwent laparoscopic surgery in Beijing Hospital. Patients' age ranged from 27 to 92 years old and was followed-up every 3 months up to 2 years, then every 6 months up to 5 years and annually afterwards until they died. The median follow-up was 47 months (ranging from 3 to 82 months); the last follow-up was in December 2015. Blood specimen for laboratory test was withdrawn just before surgery was performed. The median overall survival of patients with high PNI score ( $\geq 44.55)$ was 70.2 months (95\% CI: 66.1 to 74.2 months), whereas the median OS of patients with low PNI score $(<44.55)$ was 47.1 months $(95 \%$ 
CI: 42.9 to 51.2 months). Multivariate analysis on postoperative severe complications resulted in an OR of 4.03 (95\% CI 1.10 to 14.71]; $p=0.035$. $^{7}$

Jian Hui et $\mathrm{al}^{6}$ and most of studies set the optimal cut off value of PNI at 45 , according to receiver operating characteristic (ROC) analysis for 5 -year overall analysis. Patients in the low PNI consider to have a greater aggressive histological features of cancer.

Tokunaga et al did a retrospective study in 2017. The study enrolled 468 patients aged more than 18 years with primary colorectal cancer and underwent colectomy in Kumamoto University Hospital, Japan between March 2005 and August 2014. Patients were then followed-up till July 31 , 2016 , or death with a mean follow-up of 48.5 months (ranged from 2 to 124 months). Blood test was done two weeks before surgery. The study results showed that PNI and modified Glasgow prognostic score (mGPS) were associated with overall survival and relapse-free survival (RFS). PNI score was low if $<45$. Multivariate analyses showed that PNI score on overall survival was HR = 2.89 [95\% CI 1.81 to 4.64]; $p<0.001$; while PNI analysis on RFS was HR $=2.31[95 \%$ CI 1.53 to 3.48]; $p<0.001 .^{8}$

Park et al did a retrospective study on 1035 patients with a median age of 65 years old (ranging from 56 to 71 years old) in National University Hospital Seoul. Subjects were patients who underwent surgery for primary colorectal cancer between January 2002 and December 2010. Blood test was done 4 weeks before surgery. Follow-up was done every three months in the first two years, every 6 months for the next three years and then annually afterward. The median time of follow-up was 66 years ( 2 to 140 months). The study results show that the American Society of Anesthesiologists (ASA) score, age, tumor location, the number of lymph node involvement, vein invasion, perineural invasion, adjuvant therapy, and PNI were significant prognostic factors. The PNI score of $<45.5$ was predictive for disease-free survival (DFS) $(\mathrm{HR}=1.534 ; 95 \%$ CI 1.065 to 2.211 ; $p=0.022)$ and overall survival $(\mathrm{HR}=1.915 ; 95 \%$ CI 1.286 to 2.852 ]; $p=0.001 .^{9}$

Tokunaga et al in 2015 did a retrospective study on 556 patients with primary colorectal cancer underwent a colectomy at Kumamoto University Hospital, Japan, between March 2005 and August 2014. Patients' age ranged from 63 to 83 years.
Laboratory test was done two weeks before surgery. Patients were followed-up till death or till November 20,2014 , with a mean follow-up of 31.8 months (1 to 104 months). The study results indicated that PNI score of $<45.5$ was an independent risk factor of postoperative complication $(\mathrm{OR}=2.06 ; 95 \% \mathrm{CI}$ 1.22 to $3.50 ; p=0.007)$ and overall survival $(\mathrm{HR}=$ $3.98 ; 95 \%$ CI 2.38 to 6.89 ]; $p<0.001) .{ }^{10}$

Predictor of survival is also determined by systemic inflammatory responses, reflected by lymphocyteto-monocyte ratio (LMR), neutrophil-to-monocyte ratio (NMR), platelet-to-lymphocyte ratio (PLR), and C-reactive protein (CRP). PNI had positive correlation with LMR $(r=0,483, p<0,001)$, but negative correlation with $\operatorname{NLR}(r=-0,441, p<0,001)$, PLR $(r=-0,607, p<0,001)$, and CRP level $(r=-$ $0,333, p<0,001)$. A low PNI was associated with short overall survival and disease free survival in patients with stage III C colon cancer but not in patients with stage III A or III B. Patients with stage III $\mathrm{C}$ may have a higher tumor burden with more complex systemic pro inflammatory cytokines than those are with lower stage. Therefore, preoperative PNI has significantly correlated with immunological status. $^{11}$

In conclusion, based on the publications appraised in this evidence-based case reports, preoperative PNI score can assess the overall survival of postoperative patients with colorectal cancer of various stages, either laparoscopically or conventionally. The overall survival of colorectal cancer patients with PNI $\geq 44.5$ showed an HR between 1.92 and 3.98. The PNI score can also be used to assess DFS and postoperative complication. Thus, PNI should be evaluated before surgical treatment to predict the patient's postoperative prognosis. If the PNI score is low $(\mathrm{P}<44.5)$, the nutritional status should be improved (in terms of serum albumin level and lymphocyte count) before surgical treatment to prolong the patient's survival. 


\begin{tabular}{|c|c|c|c|}
\hline Database & Terminology & Hits & Eligible \\
\hline PubMed & $\begin{array}{l}((((((\text { prognostic nutritional index[MeSH Terms] }) \text { OR prognostic nutritional } \\
\text { index[Title/Abstract])) AND ((colorectal cancer[MeSH Terms]) OR colorectal } \\
\text { cancer[Title/Abstract])) AND ((postoperative[MeSH Terms]) OR } \\
\text { postoperative[Title/Abstract])) AND ((((survival[Title/Abstract]) OR } \\
\text { survival[MeSH Terms]) OR outcome[MeSH Terms]) OR } \\
\text { outcome[Title/Abstract])) }\end{array}$ & 21 & 5 \\
\hline Cochrane & $\begin{array}{l}\# 1 \text { (pni):ti,ab,kw OR (prognostic nutritional index):ti,ab,kw (Word variations } \\
\text { have been searched) } \\
\# 2 \text { MeSH descriptor: [Nutrition Assessment] explode all trees } \\
\# 3 \# 1 \text { or } \# 2 \\
\# 4 \text { (outcome):ti,ab,kw OR (survival):ti,ab,kw (Word variations have been } \\
\text { searched) } \\
\# \text { MeSH descriptor: [Colorectal Neoplasms] explode all trees } \\
\# 6 \text { (colorectal cancer):ti,ab,kw } \\
\# 7 \# 5 \text { or \#6 } \\
\# 8 \text { (postoperative):ti,ab,kw OR (surgery):ti,ab,kw (Word variations have been } \\
\text { searched) } \\
\# 9 \# 3 \text { and } \# 4 \text { and } \# 7 \text { and \#8 }\end{array}$ & 3 & 0 \\
\hline
\end{tabular}

Table 2. Study characteristics

\begin{tabular}{|c|c|c|c|c|c|c|c|c|}
\hline 窇 & 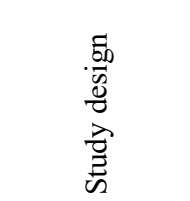 & 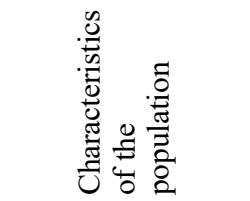 & 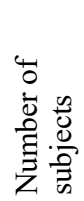 & 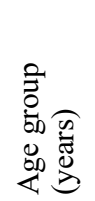 & 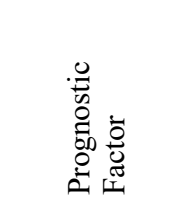 & 㭶 & $\begin{array}{l}\text { : } \\
\text { : } \\
\stackrel{0}{0}\end{array}$ & 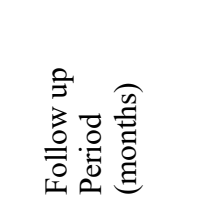 \\
\hline $\begin{array}{l}\text { Mohri Y, } \\
\text { et al } \\
(2013)^{3}\end{array}$ & $\begin{array}{l}\text { Retrospetive } \\
\text { Cohort }\end{array}$ & $\begin{array}{c}\text { Postoperative } \\
\text { colorectal cancer } \\
\text { patients }\end{array}$ & 365 & $\mathrm{n} / \mathrm{a}$ & PNI Score & - & $\begin{array}{c}\text { Overall } \\
\text { survival }\end{array}$ & $>16$ \\
\hline $\begin{array}{l}\text { Cao X, et } \\
\text { al }(2017)^{5}\end{array}$ & $\begin{array}{c}\text { Retrospetive } \\
\text { Cohort }\end{array}$ & $\begin{array}{l}\text { Post-laparoscopic } \\
\text { surgical } \\
\text { colorectal cancer } \\
\text { patients }\end{array}$ & 228 & $>18$ & PNI Score & - & $\begin{array}{c}\text { Overall } \\
\text { survival and } \\
\text { complications }\end{array}$ & $47(3-82)$ \\
\hline $\begin{array}{l}\text { Tokunaga } \\
\text { R, et al } \\
(2017)^{6}\end{array}$ & $\begin{array}{l}\text { Retrospetive } \\
\text { Cohort }\end{array}$ & $\begin{array}{l}\text { Colorectal cancer } \\
\text { patients who } \\
\text { underwent } \\
\text { surgical treatment }\end{array}$ & 468 & $>18$ & $\begin{array}{c}\text { Systemic } \\
\text { inflammation } \\
\text { scores and } \\
\text { nutrition } \\
\text { (NLR, } \\
\text { prognostic } \\
\text { index (PI), } \\
\text { PLR, PNI) }\end{array}$ & $\begin{array}{c}\text { modified } \\
\text { Glasgow } \\
\text { prognostic } \\
\text { score } \\
\text { (mGPS) } \\
\text { and TNM }\end{array}$ & $\begin{array}{c}\text { Overall } \\
\text { survival }\end{array}$ & $48.5(2-124)$ \\
\hline $\begin{array}{l}\text { Park BK, } \\
\text { et al } \\
(2016)^{7}\end{array}$ & $\begin{array}{l}\text { Retrospetive } \\
\text { Cohort }\end{array}$ & $\begin{array}{c}\text { Stage II A } \\
\text { Colorectal cancer } \\
\text { patients }\end{array}$ & 1035 & $56-71$ & $\begin{array}{c}\text { Systemic } \\
\text { inflammation } \\
\text { score (NLR, } \\
\text { dNL PLR, } \\
\text { PNI, and } \\
\text { serum } \\
\text { fibrinogen) }\end{array}$ & - & $\begin{array}{l}\text { Overall } \\
\text { survival }\end{array}$ & $66(2-140)$ \\
\hline $\begin{array}{l}\text { Tokunaga } \\
\mathrm{R} \text {, et al } \\
(2015)^{8}\end{array}$ & $\begin{array}{c}\text { Retrospective } \\
\text { Cohort }\end{array}$ & $\begin{array}{l}\text { Postoperative } \\
\text { colorectal cancer } \\
\text { patients }\end{array}$ & 556 & $63-83$ & PNI Score & - & $\begin{array}{c}\text { Severe } \\
\text { complications, } \\
\text { recurrence, } \\
\text { and overall } \\
\text { survival }\end{array}$ & $31.8(1-104)$ \\
\hline
\end{tabular}


Table 3. Validity criteria

\begin{tabular}{|c|c|c|c|c|c|c|c|c|c|c|}
\hline \multirow{2}{*}{$\begin{array}{l}\text { Validity } \\
\text { Authors }\end{array}$} & \multicolumn{8}{|c|}{ Relevance } & \multirow[b]{2}{*}{ Result } & \multirow[b]{2}{*}{$\begin{array}{c}\text { Level of } \\
\text { Evidence }\end{array}$} \\
\hline & 音.尹 & $\begin{array}{l}3 \\
3 \\
3 \\
0 \\
0 \\
0\end{array}$ & 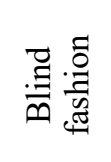 & 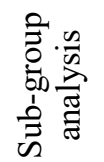 & 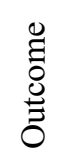 & $\begin{array}{l}0 \\
\frac{n}{2} \\
\stackrel{0}{0} \\
2\end{array}$ & $\frac{\lambda}{2}$ & 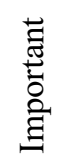 & & \\
\hline $\begin{array}{l}\text { Mohri Y, et al } \\
(2013)^{3}\end{array}$ & + & + & - & + & + & + & + & + & $\mathbf{A}$ & 2 \\
\hline $\begin{array}{l}\text { Cao X, et al } \\
(2017)^{5}\end{array}$ & + & + & - & + & + & + & + & + & B & 2 \\
\hline $\begin{array}{l}\text { Tokunaga R, et al } \\
(2017)^{6}\end{array}$ & $+/-$ & + & - & + & + & + & + & + & $\mathrm{C}$ & 2 \\
\hline $\begin{array}{l}\text { Park BK, et al } \\
(2016)^{7}\end{array}$ & + & + & - & + & + & + & - & - & D & 2 \\
\hline $\begin{array}{l}\text { Tokunaga R, et al } \\
(2015)^{8}\end{array}$ & + & + & - & + & + & + & + & + & $\mathbf{E}$ & 2 \\
\hline
\end{tabular}

A. Subjects with low PNI was associated with low postoperative survival $(p<0,0001)$;

B. Low PNI score is an independent factor associated with postoperative complication and overall survival of colorectal cancer patient $(p<0.001)$.

C. PNI score and mGPS are independent prognostic factors for overall survival and relapse-free survival of postoperative colorectal cancer patients $(p<0.001)$. The PNI score can predict the patient's survival more clearly than the mGPS combined with TNM staging.

D. PNI score can be used for overall survival of stage II colorectal cancer patients postoperatively $(p=0.001)$.

E. Subjects with PNI score $\leq 45.5$ had shorter overall survival $(p<0.001)$.

Table 4. Relevance criteria

\begin{tabular}{lccc}
\hline Article & $\begin{array}{c}\text { Similarity } \\
\text { Population }\end{array}$ & $\begin{array}{c}\text { Similarity determinant/ } \\
\text { intervention/ indicators }\end{array}$ & $\begin{array}{c}\text { Similarity } \\
\text { Outcome }\end{array}$ \\
\hline Mohri Y, et al $(2013)^{3}$ & + & + & + \\
Cao X, et al $(2017)^{5}$ & + & + & + \\
Tokunaga R, et al $(2017)^{6}$ & + & + & + \\
Park BK, et al $(2016)^{7}$ & - & + & + \\
Tokunaga R, et al $(2015)^{8}$ & + & + & + \\
\hline
\end{tabular}

Table 5. Results from critical appraisal

\begin{tabular}{lcccc}
\hline Study & Outcome & n & HR & 95\% CI \\
\hline Mohri Y, et al $(2013)^{3}$ & Overall survival & 365 & $2.29^{*}$ & 1.42 to 3.59 \\
Cao X, et al $(2017)^{5}$ & Overall survival and complications & 228 & $70.2^{* *}$ & 66.1 to 74.2 \\
Tokunaga R, et al $(2017)^{6}$ & Overall survival & 468 & 2.89 & 1.81 to 4.64 \\
Park BK, et al $(2016)^{7}$ & Overall survival & 1035 & 1.92 & 1.29 to 2.85 \\
Tokunaga R, et al $(2015)^{8}$ & Severe complications, recurrence and & 556 & 3.98 & 2.38 to 6.89 \\
\hline
\end{tabular}

* Odds ratio; $* *$ months; $\mathrm{HR}=$ hazard ratio; $\mathrm{CI}=$ confidence interval

\section{Conflict of Interest}

Authors declared no conflict of interest regarding this study.

\section{Open Access}

This article is distributed under the terms of the Creative Commons Attribution 4.0 International Licence

(http://creativecommons.org/licenses/by/4.0/), 
which permits unrestricted use, distribution, and reproduction in any medium, provided you give appropriate credit to the original author(s) and the source, provide a link to the Creative Commons license, and indicate if changes were made.

\section{Reference}

1 Bray F, Ferlay J, Soerjomataram I, Siegel RL, Torre LA, Jemal A. Global cancer statistics 2018: GLOBOCAN estimates of incidence and mortality worldwide for 36 cancers in 185 countries. CA: A cancer journal for clinicians 2018;68(6):394-424. [Google Scholar]

2 Bray F, Ferlay J, Soerjomataram I, Siegel RL, Torre LA, Jemal A. Global cancer statistics 2018: GLOBOCAN estimates of incidence and mortality worldwide for 36 cancers in 185 countries. CA: A cancer journal for clinicians 2018;68(6):394-424. [Google Scholar]

3 Abdullah M, Sudoyo AW, Utomo AR, Fauzi A, Rani AA. Molecular profile of colorectal cancer in Indonesia; is there another pathway. Gastroenterol Hepatol Bed Bench 2012;5(2):7178. [Google Scholar]

4 Basir I, Rudiman R, Lusikoy R, Lukman K, Jeo WS, AH R, et al. Pedoman Nasional Pelayanan Kedokteran Kolorektal. In: Indonesia KKR, editor. Jakarta 2017.

5 Mohri Y, Inoue Y, Tanaka K, Hiro J, Uchida K, Kusunoki M. Prognostic nutritional index predicts postoperative outcome in colorectal cancer. World J Surg 2013;37:2688-92. [Google Scholar]

6 Jian-hui C, Iskandar EA, Cai SI, Chen CQ, Wu $\mathrm{H}, \mathrm{Xu} \mathrm{JB}$, et al. Significance of Onodera's prognostic nutritional index in patients with colorectal cancer: a large cohort study in a single Chinese institution. Tumor Biology 2016 Mar;37(3):3277-83. [Google Scholar]

7 Cao X, Zhao G, Yu T, An Q, Yang H, Xiao G. Preoperative Prognostic Nutritional Index
Correlates with Severe Complications and Poor Survival in Patients with Colorectal Cancer Undergoing Curative Laparoscopic Surgery: A Retrospective Study in a Single Chinese Institution. Nutr Cancer 2017;69:454-63. [Google Scholar]

8 Tokunaga R, Sakamoto Y, Nakagawa S, Izumi D, Kosumi K, Taki K, et al. Comparison of systemic inflammatory and nutritional scores in colorectal cancer patients who underwent potentially curative resection. Int J Clin Oncol 2017;22:7408. [Google Scholar]

9 Park BK, Park JW, Han EC, Ryoo SB, Han SW, Kim TY, et al. Systemic inflammatory markers as prognostic factors in stage IIA colorectal cancer. J Surg Oncol 2016;114:216-21. [Google Scholar] 10 Tokunaga R, Sakamoto Y, Nakagawa S, Izumi D, Kosumi K, Taki K, et al. Comparison of systemic inflammatory and nutritional scores in colorectal cancer patients who underwent potentially curative resection. Int J Clin Oncol 2017;22:7408. [Google Scholar]

11 Park BK, Park JW, Han EC, Ryoo SB, Han SW, Kim TY, et al. Systemic inflammatory markers as prognostic factors in stage IIA colorectal cancer. J Surg Oncol 2016;114:216-21. [Google Scholar]

12 Tokunaga $R$, Sakamoto $Y$, Nakagawa S, Miyamoto Y, Yoshida N, Oki E, et al. Prognostic Nutritional Index Predicts Severe Complications, Recurrence, and Poor Prognosis in Patients With Colorectal Cancer Undergoing Primary Tumor Resection. Dis Colon Rectum 2015;58:1048-57. [Google Scholar]

13 Peng J, Zhang R, Zhao Y, Wu X, Chen G, Wan $\mathrm{D}$, et al. Prognostic value of preoperative prognostic nutritional index and its associations with systemic inflammatory response markers in patients with stage III colon cancer. Chin J Cancer 2017;36:96. [Google Scholar] 